\title{
MIGUEL DE UNAMUNO: UNA COMPRENSIÓN DE SU PENSAMIENTO EN TORNO A LA AGONÍA Y LA MUERTE ${ }^{1}$
}

\author{
FRANK BOLÍVAR VITERI BAZANTE \\ Universidad Politécnica Salesiana - Ecuador \\ EDWARD ANDRÉS POSADA GÓMEZ \\ Universidad Pontificia Bolivariana - Colombia
}

\begin{abstract}
RESUMEN: El presente trabajo pretende analizar el problema de la agonía y la muerte en el pensamiento de Miguel de Unamuno, como estos dos aspectos innegables en la vida del hombre se constituyen en el fundamento del filosofar y del existir. La lucha encarnizada por no morir generará en el autor una duda muy grande a la que no se la puede negar pero que estará presente en todo el proceso vital del ser humano, para después dar paso a unas alternativas de pervivencia que el mismo autor presenta pero que no logran convencerlo como una solución final.
\end{abstract}

PALABRAS CLAVE: agonía; muerte; Unamuno; pervivencia; vida.

\section{Miguel de Unamuno: An understanding of his thought in agony and death.}

ABSTRACT: This paper aims to analyze the problem of agony and death in the work of Miguel de Unamuno, how two undeniable aspects in a man's life the foundation of philosophizing and existence. The fierce struggle against death will bring into account an undeniable doubt that will be present along a human being's life, furthermore, several survival alternatives will be presented by Unamuno, for whom they did not represent a final solution.

KEY WORDS: Agony; death; Unamuno; survival; life.

Miguel de Unamuno, siendo un filósofo no tradicional y diferente, va a romper con los esquemas preestablecidos en su época, direccionando su obra hacia la reflexión sobre el hombre concreto al que el mismo autor llamará de "carne y hueso». Una filosofía vitalista e irracionalista que parte de la experiencia concreta y subjetiva para entender la existencia de cada uno de los individuos, marcado claramente por la angustia y la contradicción como fundamentos de la vida. Los cuestionamientos unamunianos existen en todos los seres humanos, de ahí que cuando al abrir uno de sus textos cuestiona no sólo la razón, sino la existencia. Cada una de sus obras se constituye en un interrogante de la condición humana.

La filosofía de Unamuno pone como centro de su reflexión al hombre que lucha encarnizadamente por no morir, asumiendo el reto de buscar la pervivencia de una manera total desde esta lucha, ya que, como dice el autor: «tiemblo ante la idea de tener que desgarrarme de mi carne; tiemblo más

1 Este artículo surge como una continuación de la investigación realizada para la tesis doctoral que lleva por título: «El problema de la muerte en la filosofía de Miguel de Unamuno: una resignificación de la agonía para comprender el sentido de la vida», a ser presentada en Universidad Pontificia Bolivariana por Msc. Frank Bolívar Viteri Bazante bajo la dirección del Dr. Edward Andrés Posada Gómez. 
aun ante la idea de tener que desgarrarme de todo lo sensible y materia, de toda sustancia $»^{2}$. Las visiones objetivas y subjetivas de la condición humana se conjugan en este autor de ahí que no es una concepción racionalista o espiritualista de la vida humana, sino parte de la realidad del hombre integral y biológico que evidencia su angustia ante el tener que morir. Rechaza conceptos románticos que lo comprendan como una idea, para aterrizar al humano real que sabe que morirá entendiendo a la muerte como la desaparición del hombre completo: biológico, psicológico, espiritual y social:

La muerte no es solo la descomposición de un organismo vivo, sino el desmoronamiento de la existencia humana, es decir, la imposibilidad de vivir la vida personal en el mundo y de seguir manteniendo una relación de amor con los seres queridos. Es, por tanto, una separación violenta del mundo y en particular, de las personas para las que vivimos. ${ }^{3}$

Unamuno comprende el hecho de morir como una ruptura de lo humano en su totalidad, por lo que el hombre, el real y concreto, se interroga y cuestiona a sí mismo, desde que nace y se desarrolla en el mundo y se preocupa por su finalidad como ser humano que vive en un afán de no morirse:

El nuestro es otro, el de carne y hueso; yo, tú, lector mío; aquel otro de más allá, cuantos pensamos sobre la Tierra. Y este hombre concreto, de carne y hueso, es el sujeto y el supremo objeto a la vez de toda filosofía, quiéranlo o no ciertos sedicentes filósofos. ${ }^{4}$

La reflexión unamuniana es contestataria a los sistemas filosóficos tradicionales, de aquellos que han hecho del hombre una idea, con sus elucubraciones racionales, llamando a la comprensión de la filosofía como una reflexión sobre la vida y la muerte. Aterrizando su filosofía en un vitalismo que permite al hombre reconocer en sí, una contingencia real, por eso es que el hombre come, juega, duerme, sufre, quiere, pero también muere, he ahí la causa del ansia de no morir, por lo que dice que: el secreto de la vida humana es que de ella siempre brotará ansia de vivir más ${ }^{5}$. No puede comprenderse al «yo» no existiendo y el intento de esta comprensión genera una angustia, lo cual va a influir en la estructura del sentido de la vida por lo que no puede comprender al hombre sin proyección hacia un sentido, dejando de lado la reflexión sobre su muerte, pues la interpelación estará presente ante la inmanencia de la muerte en nuestra vida. Entonces la interrogante de la intencionalidad de la vida surge en la vida misma.

Unamuno no es un autor estructurado desde una sola perspectiva, sino que como afirma Marías: «filosofía, literatura, religión, poesía, estarían luchando y

2 De Unamuno, M. (2009). Del sentimiento trágico de la vida. Salamanca: Fundación Antonio de Castro, 312.

3 GeVAert, J. (2013). El problema del hombre. Salamanca: Sígueme.

4 De Unamuno, M. Del sentimiento trágico de la vida, 375.

5 De Unamuno, M. (2009). Agonía del Cristianismo. Salamanca: Fundación Antonio de Castro. 
contradiciéndose en cada libro, en cada frase; intentar clasificar a Unamuno sería tan absurdo como vano» ${ }^{6}$. Unamuno no quiso, ni pretenderá jamás en su vida, desarrollar un manual de filosofia encasillado en un pensamiento particular sino que sus textos aparecerán desde los cuestionamientos existenciales que surgen a lo largo de su vida, de ahí que inclusive muchas veces no se puede decir si nuestro autor es filosofo, literato, poeta, pero sí un fecundo escritor que plasma su vida en su obra por lo que es absurdo decir que esta todo dicho sobre él:

(...), la inmensa bibliografía sobre su obra puede llevar a pensar que ya está todo dicho sobre él. Sin embargo, el lector de sus textos siempre encuentra algo por descubrir entre las más de 12.000 páginas que componen sus escritos. $^{7}$

La obra de este autor es extensa, variada, confusa, apelante, demandante y algunas veces suplicante y desde allí se acerca a distintas dimensiones del saber humano como: literatura, poesía, filosofía, educación, psicología, etc., con una perspectiva vitalista en la que el centro de todo este accionar es el hombre: el hombre concreto, «el de carne y hueso» que sabe que va a morir, lo que genera en él un deseo "por no morir», es decir, una agonía (entendida como lucha constante).

Escribirá varias llamadas de atención, presentando una actualidad inmanente sobre un cuestionamiento eterno, el problema del hombre y de su vida. Con él se entra en un diálogo confuso y difícil no exento de contradicciones internas. Esto le llevara a constituirse en una figura polémica para sus contemporáneos. Dueño de una capacidad para escribir inagotable y variopinta, se constituirá en uno de los más grandes pensadores de España:

La cosa empezaba por la figura corporal; don Miguel, con su menuda cabeza de búho inquietante, inolvidable e inconfundible, su silueta esbelta y recia, su modo de vestir sencillo y un tanto inusitado, sus pajaritas de papel y su miga de pan, ha sido durante muchos años un elemento pintoresco, azorante, curioso de la vida española; algo que «había que ver», que se enseñaba, que todos, incluso los que nunca pensaban leerlo, conocían. ${ }^{8}$

La figura unamuniana se constituye en una referencia no sólo para su contexto, sino que su obra tiene una constante actualidad como la preocupación por el hombre mismo.

\section{Agonía y muerte: CONSTANTE de La obra UnAMUniana}

Hablar del pensamiento de Miguel de Unamuno, exige un ejercicio de comprensión integral del autor como hombre y como escritor; donde el punto

6 Marías, J. (1953). El existencialismo en España. Bogota: Universidad Nacional de Colombia, 83-84.

7 Villar Ezcurra, A. (2014). «El orden del amor en Miguel de Unamuno». Dialegesthai. Revista telematica di filosofia [en linea], anno 16. <http://mondodomani.org/dialegesthai/>, $[* * 41 \mathrm{~B}]$, ISSN.

8 Marías, J. (1948). La Filosofía española actual. Buenos Aires: Austral, 32. 
de partida de la reflexión unamuniana será la subsistencia, la aferrada rebelión ante el hecho de dejar de ser, un problema ontológico que lo hereda de Espinoza, «el perseverar en el ser» ${ }^{9}$. Este perseverar impactará de tal manera en el autor vasco, que enseguida lo concatenará con su filosofía, con su lucha incansable por no morir. De ahí que su hambre de inmortalidad se convierta en parte de su vida para establecerlo como un eje transversal en toda su obra.

No se queda en el concepto ideal o racional del ser, sino que aterriza su filosofía y su deseo de inmortalidad en el hombre concreto que al vivir en su cotidianidad no quiere morir, pero morirá. La conciencia de la muerte estará siempre presente, al igual que la sed de vida perpetua y de vida cada vez más plena choca con el obstáculo dirimente de la muerte, que parece invencible ${ }^{10}$. No es una paradoja en la que se enfrasca Unamuno y que muere con él, sino que se constituye en una invitación para todos, una tragedia compartida en la que nos obliga a pensar a todos: su pensamiento fue de contradicción, razón por la cual hoy se mantiene vivo. El no sólo pensó y dudó, sino que hace pensar y dudar ${ }^{11}$. De ahí que hasta el mismo lenguaje se modifique comprendiendo que éste «es producto del ambiente, y según el conexionismo-asociacionismo hay que recordar que la asociación no es un evento lógico sino somático-sensorial, es decir, está dado por la proximidad de cuerpos, en la que se crean redes sensoriales ${ }^{12}$ donde expresar el hecho de la muerte. Este acontecimiento se somete a tal falta de proximidad y tal soledad, que resulta inexplicable con el lenguaje racional, requiriendo de la constitución de ritos en torno a ella.

\subsection{El problema de la agonía en la obra Unamuniana}

Antes de empezar el análisis de la agonía en Miguel de Unamuno, conviene realizar un análisis etimológico y contextual de este término para estructurar un análisis lingüístico que no deje de lado dudas, de ahí que en griego existen también dos términos para expresar la agonía, el primero con omicron,

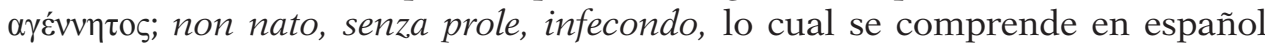
como sin generación, infecundo, estéril ${ }^{13}$. A lo cual el hombre no quiere llegar, el sin nacimiento y la infecundidad produce angustia y dolor pues no hay continuidad de la existencia, con estos términos se cancela el fin último del hombre, que es querer vivir eternamente, aunque este término no denota lucha, se concluye desde aquí que siempre el hombre huirá a estos estados pues son de cierto modo anti-natura y cierran el proyecto de vida del hombre.

9 Spinoza, B. (1980). Ética. Demostrada según el orden geométrico. Madrid: Orbis, 131.

10 GuY, A. (1985), Historia de la Filosofía Española. Madrid: Anthropos.

11 Agüero, E. (1968). El pensamiento filosófico y religioso de Unamuno. New York: APP.

12 SANMARTín, R. (2016). «El lenguaje incorporado desde y para la cognición incorporada». Sophia: Colección de filosofía de la educación, 21-64. DOI: 10.17163/soph.n20.2016.01, Universidad Politécnica Salesiana.

13 Rocci (1944). Vocabolario. Greco - Italiano. Genova: Societá Anima Dante Alighieri. 


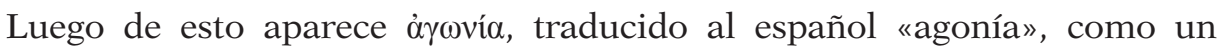
término que si denota lucha, agitación, angustia ${ }^{14}$. Viene del sufijo acción y la raíz lucha o combate, aunque por lo general se lo relaciona con el estado anterior a la muerte. Se trata de un estado pre-morten en el cual la persona lucha por sobrevivir a pesar de que está en la última etapa, pero en general es lucha.

Así resulta que ảy de equivalencia lógica, aunque parecen diferentes, pero en la realidad humana se constituyen en una similitud ya que los significados nos llevan por caminos diferentes a la conclusión de que el hombre lucha, pelea por no morir. Veremos que en algunas de sus obras se presentará textualmente esta acepción en el desarrollo de su teoría citando repetidamente la segunda concepción griega de agonía. Aprecia y recibe este término como tal para presentar su filosofía y su vida: «Miguel de Unamuno se definió siempre como un luchador: “(...) te imaginas luchar por la victoria, y yo lucho por la lucha misma (...) La paz es sumisión y mentira. Ya conoces mi divisa: primero verdad que la paz" ${ }^{16}$. Se comprende la agonía como búsqueda incesante de vida con todas sus implicaciones ontológicas del hombre como ser que lucha, que no está estático, sino que al ser vida se mueve en todas sus dimensiones humanas.

Siempre se encontrará en una lucha constante entre las dicotomías del yo: razón y corazón, que el mismo autor vivió, fundamentando en esta lucha la constante inquietud que mueve en la vida: «la agonía, a diferencia de la ataraxia, implica inquietud. Pero lo característico de esta inquietud es su carácter constitutivo» ${ }^{17}$. Factor que se cumple de manera evidente, ya que la lucha se constituirá en un elemento ontológico de la experiencia, nadie podrá prescindir de aquella lucha que lleva en su interior.

Al ser la obra unamuniana autobiográfica, se va a reflejar constantemente esta agonía o lucha en todos los aspectos de su vida: familia, antropología, política, literatura, filosofía, etc. Todo será una manifestación de esa lucha encarnizada que a veces tiene consigo mismo, con Dios o con los otros, tal es así que en tercera persona el autor se presenta como tal:

Tal es la agonía de don Miguel de Unamuno, hombre en lucha, en lucha consigo mismo, con su pueblo y contra su pueblo, hombre hostil, hombre de guerra civil, tribuno sin partidarios, hombre solitario, desterrado, salvaje, orador en el desierto, provocador, vano, engañoso, paradójico, inconciliable, irreconciliable, enemigo de la nada y a quien la nada atrae y devora,

\footnotetext{
14 RoccI, op. cit.

15 Pabon, J. (1967). Manual Griego. Madrid: Vox.

16 Blanco Ilari, J. (2011). «Lo agonal y lo ireneico en la filosofía». Tábano, 7: 66 http://bibliotecadigital.uca.edu.ar/repositorio/revistas/agonal-ireneico-filosofia-ilari.pdf, Universidad Católica de Argentina. El pasaje citado se encuentra en: Unamuno, M. Mi religión y otros ensayos, Buenos Aires, Austral Espasa Calpe, 1945, 25.

17 Blanco IlaRi, J. «Lo agonal y lo ireneico en la filosofía», 63.
} 
desgarrado entre la vida y la muerte, muerto y resucitado a la vez, invencible y siempre vencido. ${ }^{18}$

Siempre estará aquel conflicto muy dentro de él, se presentará como un agonizante por excelencia de ahí que usa la tercera persona verbal para poder describirse de una manera más precisa, como el sujeto que necesita ser analizado. Adjetivos y verbos muy duros, pero a la vez reales, acompañarán siempre esta agonía, tratando de pasarle al lector el cuestionamiento sobre la agonía que en cada historia se vive, donde el luchar no se reduce al estado inmediatamente anterior a la muerte, sino una lucha como vida.

El mismo Unamuno presenta claramente en el prólogo a su obra La Agonía del Cristianismo una invitación primera para conocer la etimología y significado de esta palabra, y equiparará a la agonía con la vida, sin hacer distinción pues al igual que el hombre son una sola: «Agoniza el que vive luchando, luchando contra la vida misma ${ }^{19}$. Esta lucha es común en todos los hombres, pues el hombre concreto de carne y hueso, luchará en esta vida, lo cual muestra de la siguiente manera:

La vida es lucha, y la solidaridad para la vida es lucha y se hace en la lucha. No me cansaré de repetir lo que más nos une a los hombres unos con otros son nuestras discordias. Y lo que más le une a cada uno consigo mismo, lo que hace la unidad íntima de nuestra vida son nuestras discordias íntimas, las contradicciones interiores de nuestras discordias. ${ }^{20}$

En esta lucha los contrincantes serán el corazón y la razón, donde cada uno de estos permitirá reafirmar nuestra vida, para comprender que estamos siempre en una lucha por vivir. Como en la antigua Grecia, Unamuno hace el llamado para no caer en el eterno olvido, ese que atormentaba a los guerreros y luchadores griegos, igual atormenta al hombre de carne y hueso.

Al igual que los griegos la agonía estará unida a la actividad, no será una agonía pasiva en la cual el hombre mira hacia arriba esperando que algo acontezca, sino que Unamuno se presentará como un hombre que agoniza en actividad, aunque conozca la tragedia de la vida: «la resignación o desesperación activa sabe sacar fuerzas de la propia flaqueza para no dimitir ${ }^{21}$. Entonces ante aquellas luchas la vida del hombre no se niega en el destierro de la quietud y de hacerlo, negamos el yo de aquel hombre de carne y hueso que sigue precedido de varios verbos que denotan acción: «se puede morir sin agonía y se puede vivir, y muchos años, en ella y de ella. Un verdadero agonizante es un agonista, protagonista unas veces, antagonista otras $»^{22}$.

18 De Unamuno, M. (1999). Como se hace una novela. Salamanca: Fundación José Antonio de Castro, 552.

19 De Unamuno. Agonía del Cristianismo, 545.

20 De Unamuno. Agonía del Cristianismo, 646.

21 Cerezo Galán, P. (1996). Las Mascaras de lo Trágico. Madrid: Trotta, 248.

22 De Unamuno. Agonía del Cristianismo. 539. 


\subsection{La lucha como contradicción}

La agonía en Unamuno no es sólo una lucha doliente y pasiva ante la cercanía de la muerte sino también una lucha entre elementos contradictorios en la vida del hombre, «lo agonal de este humor filosófico consiste en no poder resolverse por ninguno de los polos. No puede descansar en una afirmación absoluta ni en una negación total, pero tampoco se ve satisfecho suspendiendo el juicio» ${ }^{23}$. Estos dos puntos en don Miguel estarán presentes en toda la constitución del yo. Los contrarios unamunianos constantemente lucharán en la búsqueda del sentido y la realidad innegable del sinsentido. No llegará a ningún polo ya que es imposible en el carácter agónico, donde sólo se quiere vivir, pero no se puede hacerlo eternamente y siempre estará la premisa del tener que morir. Llegando al punto de no poder ni siquiera ignorar la lucha que en nuestro interior acontece, pues la conciencia interpelará siempre la existencia.

La agonía en Unamuno tiene una dimensión antropológica y afecta al hombre en su conjunto, no sólo a una parte. La agonía constituye ontológicamente al ser humano. La ontología unitaria del ser humano será el fundamento de la contradicción pues no se puede prescindir de ninguna de estas dos realidades: razón y el corazón que contradiciéndose constantemente llevan al hombre a vivir este sentimiento trágico de la vida. Lo cual afirmará reciamente el autor:

Alguien podrá ver un fondo de contradicción en todo cuando voy diciendo, anhelando unas veces la vida inacabable, y diciendo otras que esta vida no tiene el valor que se le da (...) ¿Contradicción? ¡Ya lo creo! ¡La de mi corazón, que dice que sí, mi cabeza, que dice que no! Contradicción, naturalmente (...) Como que sólo vivimos de contradicciones, y por ellas; como que la vida es tragedia, y la tragedia es perpetua lucha, sin victoria ni esperanza de ella; es contradicción. ${ }^{24}$

Lucha como constante cotidiana de interpelación y acción ante el evento de vivir. «por mi parte no quiero poner paz entre mi corazón y mi cabeza, entre mi fe y mi razón; quiero más bien que se peleen entre sí» ${ }^{25}$. Lo que permite comprender que para que la vida sea autentica tendrá que estar llena de entrañables contradicciones que se mueven entre los dos bandos, lo cual generará movimiento en el sentido de que desde la contradicción se proyecta en la acción.

Luego de esto aparecerá la concepción de la contradicción como duelo y duda, desde la misma raíz los significados desembocan en un término «dúo» donde la decisión adquiere un rol fundamental, lo dual hace sufrir al hombre pues este debe encaminarse hacia una de las dos opciones y aparece el problema de la decisión:

¿Y qué es dudar? Dubitare contiene la misma raíz, la del numeral dúo, dos, que duellum, lucha. La duda, más la pascaliana, la duda agónica o polémica, que no la cartesiana o duda metódica, la duda de vida, vida es lucha, y no de camino método es camino, supone la dualidad del combate. ${ }^{26}$

23 Blanco Ilari. «Lo agonal y lo ireneico», 63.

24 De Unamuno. Del sentimiento trágico de la vida, 285.

25 De Unamuno. Del sentimiento trágico de la vida, 370.

26 De Unamuno. Agonía del Cristianismo, 548. 
Las definiciones de duelo y duda muestran una sincronía entre términos comunes donde se evidencian las dos partes que están en una pugna constante, desde la comprensión de la lucha entre dos agentes. Es importante añadir a esta concepción que el término duelo también se referencia al dolor, lo cual permite direccionar la reflexión hacia el hecho de combatir como un hecho doloroso que quien gane o pierda igual lo va a sentir. Entonces a esta vida agónica comprende establecer una comprensión del duelo y la duda donde el hombre se ubica en el centro de dos opciones, dos caminos que están en duelo, en el cual solo uno es el ganador.

Esta lucha de contrarios partirá sobre todo desde la lucha de dos instintos básicos de la vida del hombre, principios constitutivos del ser humano que han hecho que a lo largo de la historia el hombre siga existiendo como especie en el mundo, de ahí que Reale y Antiseri afirmen que:

Existen dos instintos: el de conservación, individual, lógico, técnico; y el de perpetuación, voluntarista, irracional, social, con socialidad tendente a la participación en la unidad del universo, de Dios, indefectible e inmortal. Unamuno concibe estos dos instintos antagónicos como dos fuerzas colosales en colisión inmanente, eternamente equilibrada, en lucha feroz que no mata ni elimina a ninguna de ellas con la victoria definitiva de una, sino que gravita con peso de «agonía» (lucha) sobre el sujeto, el hombre que soporta en sus carnes aquel tremendo conflicto. ${ }^{27}$

Estos dos instintos buscan o se remiten en última instancia al deseo de no morir, el hambre de inmortalidad estará entregándose desde el corazón hacia la razón. Es fundamental comprender que esta dicotomía a pesar de ser a nivel instintivo tampoco tiene una solución, sino que más bien es un punto de partida para ahondar en niveles superiores del ser humano. Pues biológicamente nos constituimos de instintos que lucharán por la inmortalidad y que se constituyen como base del sentimiento trágico de la vida para establecer una comprensión de la acción existencial del hombre como ser en la existencia.

Poéticamente presentará esta paradoja para comprender que no habrá solución ante la contradicción, ni siquiera un acercamiento de olvido del problema. Simplemente el hombre deberá caminar con esta realidad hacia la fundamentación del conocimiento y la voluntad, será una proyección de razón y corazón con sus facultades que se convierten en agonía pues en sí mismas se contradirán eternamente, problema irresuelto del ser humano:

$$
\begin{aligned}
& \text { Jacob y Esaú, la vieja } \\
& \text { lucha, siempre a sucumbir } \\
& \text { por un plato de lenteja, } \\
& \text { pero plato que es vivir. }{ }^{28}
\end{aligned}
$$

27 Reale G. and Antiseri D. (1988). Historia del Pensamiento Filosófico y Cientifico: Desde el Romanticismo hasta hoy. Barcelona: Herder, 942.

28 De Unamuno, M. (1999). Cancionero. Salamanca: Fundación José Antonio de Castro, 292. 
Entonces concluye el poema realzando el valor primordial de la vida como fin último de esta lucha ya que se comprende que no se lucha para morir, no se agoniza esperando la muerte, sino que se lucha por la vida. La vida es el fundamento de la lucha que desemboca en el ansia de inmortalidad, expresando a los dos agentes del querer y el saber como producto de la clásica lucha entre razón y corazón en el ser humano.

\subsection{La lucha como contradicción en el ser social}

El autor no se queda sólo en el plano individual y personal, ya que de hacerlo sería absurdo filosofar, de ahí que él mismo considerará inexistente e imposible de concebir al hombre como individuo aislado:

Pero el hombre ni vive solo ni es individuo aislado, sino que es miembro de sociedad, encerrando no poca verdad aquel dicho de que el individuo, como el átomo, es una abstracción. Sí, el átomo fuera del universo es tan abstracción como el universo aparte de los átomos. Y si el individuo se mantiene es por el instinto de perpetuación de aquel. Y de este instinto, mejor dicho, de la sociedad, brota la razón. ${ }^{29}$

Esta comprensión del ser social permitirá que trasponga su teoría también a la sociedad, lo que denominará el sentimiento trágico de la vida y de los pueblos, pues afirmar un individuo sin sociedad sería negarlo completamente. En este sentido Unamuno es muy realista, "cada uno de nosotros vive y participa de una sociedad, de un pueblo, de unos otros con los que convive ${ }^{30}$. Su sentimiento trágico de la vida, no será solo de individuos sino también de los pueblos, de aquellos pueblos que se constituyen en base a hombres que aman y tienen empatía los unos por los otros.

No es a la individualidad agónica a la que apelará Unamuno sino más bien a aquel sentimiento trágico que se proyecta al pueblo y la sociedad para comprender que ésta se basa o encuentra fundamento en el mencionado sentimiento, partiendo al igual que el hombre de aquellos instintos de conservación y perpetuación pero trasponiéndolos a la sociedad: «El instinto de conservación, el hambre, es el fundamento del individuo humano; el instinto de perpetuación, amor en su forma más rudimentaria y fisiológica, es el fundamento de la sociedad humana ${ }^{31}$. Para al igual que el hombre pasar a aquellas luchas entre razón y corazón que desembocan en el actuar: pensar y desear. Este fundamento constituirá sociedades que luchan por preservarse como tal, en el tiempo. Los instintos son en sí la base para

29 De Unamuno. Del sentimiento trágico de la vida, 294-295.

30 Camino, A. (2013). «Los orígenes de la ontología de Unamuno» Scientia Helmantica. Revista Internacional de Filosofía, N. 2: 104, http://revistascientiahelmantica.usal.es/docs/ Vol.02/06.Camino_Aparicio.Origenes_de_la_ontologia_de_Unamuno.pdf. Universidad Pontificia de Salamanca.

31 De Unamuno. Del sentimiento trágico de la vida, 295. 
arrancar en la construcción de la sociedad en la historia con proyección hacia lo eterno, de ahí que la humanidad exista hasta el día de hoy con miles de años de historia.

Esto volcará a la lucha misma que se desarrolla en la sociedad, esa lucha en la que convergen ideales de crecimiento y de más vida como en el individuo, es decir, el concepto se transpone como ansia de inmortalidad a la sociedad, «la propia lucha que implica la historicidad y vitalidad de la sociedad humana, en donde se fragua de forma continua y persistente la tradición eterna ${ }^{32}$. Ahora bien la lucha de contrarios en la sociedad se comprenderá como un vehículo de soluciones o búsqueda de alternativas en los conflictos, es decir, la contradicción social dará paso al desarrollo de la historia como fundamento del hombre en la vida, no habrá comprensión de lo social sin entender que esta lucha de contrarios fundará el principio de continuidad histórico-social como fundamenta la inmortalidad en la vida individual del hombre, «la historia humana, que no es sino continuidad en pugna permanente» ${ }^{33}$. Pero no es un sentimiento bélico y aguerrido sino más bien un sentimiento de compasión que empuja desde el amor a proyectarse como hombre en conjunto. Necesaria e imprescindible para generar movimiento en la historia, para caminar como el hombre luchando hasta la pervivencia, la inmortalidad y la vida eterna, ya que de moverse por actos egoístas la humanidad hubiese desaparecido ${ }^{34}$, en este punto es fundamental comprender que Unamuno es un agente de lucha social muy importante para su época, lo cual más que beneficios trajo para él, una serie de complicaciones.

Se comprende que la acción en los pueblos surge también de aquella agonía constante en el hombre, de esos contrarios y de esa lucha por pervivencia. El hombre unamuniano "al ser social», no puede dejar de transmitir ese sentimiento trágico a la sociedad pues de hacerlo simplemente se negaría a sí mismo; pero se constituye en un ser que agónicamente se establece en la misma cuestionándola y generando desde ella un progreso basado en el amor como fundamento de las relaciones sociales.

Comprender el grado de relación desde la agonía va más allá del individuo con la sociedad, sino que también se aplica a esta contradicción entre pueblos que como lucha de contrarios buscan progreso e historia. No se puede comprender, así como al hombre un pueblo que no tenga un contrario, que no luche, ya que de no hacerlo caerá en el pecado de vivir de las glorias pasadas sin proyección al futuro, sin responder a su lucha por sobrevivir, de ahí que Unamuno afirmará:

32 Pascual Mezouita, E. (2007). «El principio de continuidad historica en Unamuno», Cuadernos de la Catedra Miguel de Unamuno, vol 43, 68. http://revistas.usal.es/index.php/0210749X/article/view/1561: Universidad Pontificia de Salamanca.

33 Pascual Mezouita, op. cit., p. 68.

34 Villar Ezcurra, A. (2007). "Muerte y pervivencia en Unamuno». Contrastes: Revista Internacional de Filosofia, $\mathrm{N}^{\mathrm{o}} 12$. 
Cuando un hombre se encierra en sí resistiendo cuanto puede al ambiente y empieza a vivir de sus recuerdos, de su historia, a hurgarse en exámenes introspectivos la conciencia, acaba ésta por hipertrofiarse sobre el fondo subconsciente. (...) Y así sucede a los pueblos que en sus encerronas y aislamientos hipertrofian en su espíritu colectivo la conciencia histórica a expensas de la vida difusa intra-histórica que languidece por falta de ventilación; el pensamiento nacional, trabajando hacia sí, acalla el rumor inarticulado de la vida que bajo él se extiende. Hay pueblos que en puro mirarse al ombligo nacional caen en sueño hipnótico y contemplan la nada. ${ }^{35}$

El fundamento de las relaciones sociales serán para Unamuno el amor como constitutivo de una sociedad que se forja en conjunto, es decir, los sentimientos agónicos y aquellos que pueden brotar del hombre de carne y hueso y se hacen comunes pero sobre todo se estructuran en el sentirse frágiles, al comprenderse en la finitud que cada hombre comparte con el otro ${ }^{36}$, comprendiéndose al hombre y a la sociedad como una unidad que sufre y que tiene hambre de inmortalidad. De ahí que la historia de los pueblos sea dinámica en la búsqueda de una perpetuación eterna. No es un trabajo individual o egoísta, sino que en el dinamismo del amor como punto de quiebra entre el «yo» y los «otros» se sustenta la sociedad. "Y así como el hombre conoce lo que necesita conocer para que se conserve, así la sociedad o el hombre, en cuanto ser social conoce lo que necesita conocer para perpetuarse en sociedad ${ }^{37}$.

La agonía social no se queda en el mero deseo por perpetuarse como grupo o en comunidad sino que se establece un sentido de humanidad en aquel deseo, el mismo que alguna vez fundamenta la lucha del hombre, de ahí que el fin último del ser social es establecerse en aquella sociedad infinita que no sucumbe ante la realidad temporal a la cual Unamuno teme de una manera voraz: «Es la conciencia social, hija del amor, del instinto de perpetuación, la que nos lleva a socializarlo todo, a ver en todo sociedad, y nos muestra, por último, cuán de veras es una Sociedad infinita la Naturaleza toda ${ }^{38}$. Como no se puede comprender la infinitud de la sociedad en un mundo terreno finito se busca personalizar el Universo «esta personalización del todo, del Universo, a que nos lleva el amor, la compasión, es la de una persona que abarca y encierra en sí a las demás personas que la componen ${ }^{39}$. El fin del que huye Unamuno es el de la temporalidad tanto a nivel individual como social, generando una búsqueda insaciable de aquella inmortalidad en todo el sentido de la palabra y que abarque toda la realidad.

En este sentido el pensamiento de Unamuno es clave para estructurar una sociedad con un fin común en el que el sentido de progreso se desarrolle en base a una estructuración ontológica del amor como base de la vida social, es ahí

35 De Unamuno. Agonía, 195.

36 Villar Ezcurra, A. «El orden del amor en Miguel de Unamuno».

37 De Unamuno. Del sentimiento trágico de la vida, 295.

38 De Unamuno. Del sentimiento trágico de la vida, 396.

39 De Unamuno. Del sentimiento trágico de la vida, 396. 
donde se comprende que Unamuno no se cierra a la inmortalidad individual sino que el ansia de vida brota de aquel amor con el cual deseo o anhelo que los otros se perpetúen con el individuo, pues si logro alcanzar la inmortalidad solo no habría ningún sentido en la soledad del Universo, es el fundante «yo que se relaciona con los otros» para establecer una vida interminable. Es necesaria en la actualidad esta relación, para establecer relaciones sociales basadas en la protección del otro como parte constitutiva del yo.

\section{El problema de la muerte en la filosofía de Miguel de Unamuno}

Unamuno en cada una de sus obras gritará ¡No quiero morir!, se niega a morir, ya que siempre tendrá una relación constante y muy dolorosa con la muerte a lo largo de su vida, ésta no le dejará nunca de perseguir pues desde el seno familiar, el hijo que queda huérfano de padre hasta el padre que queda "huérfano» ${ }^{40}$ del hijo, la convulsionada España que se debatía en guerras civiles y fratricidas hasta su abundante obra literaria donde una de las tramas constantes será la muerte ${ }^{41}$, de la cual, será muy claro en recalcar que la novela en Unamuno es un intento por vivir a pesar de la muerte y prueba de ello es que "en casi todas sus novelas la muerte se encuentra presente» ${ }^{42}$. El autor bilbaíno comprenderá que el hecho de morir es el problema fundamental del pensamiento y la filosofía; del arte y el pensamiento; de la razón y del corazón, del hombre de carne y hueso. De ahí que, al iniciar su obra, Del sentimiento trágico de la vida, el llamamiento será a aquel hermano que vive pero que sobre todo muere. Presupone en este sentido Miguel de Unamuno que todos sufrimos por el hecho de tener conciencia de que vamos a morir. A lo largo de su obra presentará cómo el hombre en todas sus etapas de la vida sufrirá por el hecho de tener que morir y de ahí comprenderá la vida desde la idea del tener que morir hasta la agonía como lucha constante.

\subsection{La presencia de la agonía y la muerte en el ciclo vital}

La obra de Miguel de Unamuno siendo un pensamiento en torno a la muerte, aspecto que el racionalismo y la tradición filosófica había olvidado por la conceptualización del hombre, tratando siempre de hacer una meditatio

40 Se utiliza el término huérfano al no existir otro que nombre la muerte de un hijo y nombre el estado de la madre y del padre. En palabras de Piedad Bonett, aquello innombrable, la cultura no ha logrado ni siquiera a atreverse a darle un nombre pues el lenguaje no alcanza a cumplir con el cometido.

${ }_{41}$ Marías, J. (1971). Miguel de Unamuno. Madrid: Espasa-Calpe.

42 De Unamuno Pérez, M. de C. (1998). «Unamuno lector de Balzac: La sed de eternidad». Cuadernos de la Catedra Miguel de Unamuno, vol 33(0). http://revistas.usal.es/index.php/0210749X/article/view/1697. Universidad Pontificia de Salamanca. 
mortis ${ }^{43}$, que constituye el fundamento del hombre concreto que cumpliendo su ciclo vital siempre tendrá conciencia de la última etapa de su proceso y tendrá que cumplir con las anteriores etapas esta idea. Ya que para Unamuno «vivir es darse, perpetuarse, y perpetuarse y asumiendo darse es morir ${ }^{44}$, la tragedia del hombre se constituye en la omnipresencia de la muerte en todo su trayecto vital.

\subsubsection{El nacimiento como inicio de la totalidad}

El nacimiento ha sido olvidado por muchos filósofos ${ }^{45}$, el mismo Unamuno se dará cuenta de este hecho, hemos olvidado el hecho de nuestro nacimiento ${ }^{46}$, pero siempre reflexionará en el nacimiento como el fundamento de la vida, el inicio del todo que es la vida: nacimiento y muerte — dos tránsitos, todo y nada... ${ }^{47}$. Aunque no tengamos conciencia de ellos, permiten pasar a los estados de totalidad, el nacimiento, y a un estado nihilista, la muerte. De ahí que los dos eventos son cardinales en la vida del hombre en el pasado y en el futuro, de los cuales no tenemos conciencia.

Con el nacimiento empieza la constitución del hombre y de la vida; aunque no logre definir el nacimiento tendrá claro que el nacimiento como la muerte son misterios que se constituyen en fundamentos de la vida: « ¿La muerte es un misterio? También el nacimiento lo es. ¿Cómo de los hombres salen hombres?» ${ }^{48}$. Como es característico en Unamuno no querrá sistematizar, definir o conceptualizar el nacimiento, pero sí establece la importancia que tal evento tiene en la constitución del ser humano. Unamuno no sólo menciona al nacimiento en su obra, sino que invita al lector a profundizar en el tema del nacimiento, aunque siempre esté relacionado con la muerte como inicio y como fin: «si miras con calma tu nacimiento ¿por qué no miras también con calma tu des nacimiento?» ${ }^{49}$. El nacimiento es el inicio del gozo de la vida para Unamuno, pero igual es aceptado sin la conciencia de éste. Sólo se comprende porque existimos mas no por tener conciencia del él.

En los últimos años existe una preocupación filosófica alrededor del nacimiento en el sentido de que la filosofía siempre ha sido una meditación en torno a la muerte ${ }^{50}$, y aunque no tengamos conciencia del hecho del nacimiento, este evento es fundamental para comprender al hombre, pues siempre el hombre será actualización constante de su nacimiento, del origen de su vida: «Estoy siempre después de mi nacimiento, —en un sentido análogo al

43 Marías, J. (1953). El existencialismo en España. Bogota: Universidad Nacional de Colombia.

44 De Unamuno. Del sentimiento trágico de la vida. 382.

45 Diez Fisher, F. (2012). «La filosofía y los nacidos. ¿Porqué olvidaron los filósofos el nacimiento?» Franciscanum. Vol. N. 157.

46 De Unamuno, M. (2009). Diario Íntimo.(Salamanca: Fundación José Antonio de Castro.

47 De Unamuno, M. (2009). Madrid. Salamanca: Fundación José Antonio de Castro, 81.

48 De Unamuno. Diario Íntimo, 275.

49 De Unamuno. Diario Íntimo, 387.

50 Diez Fisher, F. «La filosofía y los nacidos». 
que estoy siempre antes de mi muerte» ${ }^{51}$. El hecho de nacer siempre existirá, el hombre será testigo del nacimiento de los otros, como será testigo de la muerte de los otros, sin poder sentir el nacimiento en primera persona a pesar de ser la dimensión más influyente en la vida humana ${ }^{52}$.

El hecho del nacer es fundamental para el desarrollo de la filosofía y de la comprensión integral del ser humano, ya que el nacimiento en cuanto se da paso al mismo en constituir la vida, es un germen de todas las ramificaciones de la necesidad ${ }^{53}$. El nacimiento no se toma en cuenta por cuanto ya es acabado, «nací, estoy viviendo y ya», lo cual Unamuno respeta, pero interroga al mismo tiempo, tomando en cuenta que siempre se debe caminar hacia la construcción de un ser humano estructurado que quiere vivir eternamente, «acontecimiento primero de hecho y de derecho de la aventura mortal, con cuya vara deben ser desde entonces determinados y comprendidos todos los otros acontecimientos» ${ }^{54}$.

Unamuno en sus textos busca constituir un fundamento estructural de la comprensión del ser humano, que se va a desarrollar continuamente en su edificación que lucha por eternizarse, en la cual el haber surgido de un nacer va a influenciar claramente a lo largo de la vida. Aquí tenemos una gran discusión en el ámbito de la psicología en la que se estudia y se busca comprender la incidencia que el nacimiento y la primera infancia tienen para la constitución del ser humano adulto, que Miguel de Unamuno comprenderá para arengar al hombre a comprender el ser que va a morir: ya que como no fuimos antes de nacer no seremos después de morir, trágico destino del hombre al cual Unamuno apela para comprender al hombre de carne y hueso lejos de conceptualización o abstracción racional ${ }^{55}$. Será entonces el acontecimiento del nacimiento, que, aunque no tenga conciencia de él, fundamente la vida y la muerte como hecho inevitable de la existencia que nos cuestiona como presencia innegable. Es el inicio del camino de la vida que no quiere tener fin.

\subsubsection{La continuidad como ámbito de acción en la vida}

Unamuno no se centrará solo en pensar en la dicotomía del nacimiento o de la muerte, sino que comprenderá el término intermedio donde el crecer es fundamental en el momento de configurar al ser humano, para establecer que el hombre de carne y hueso construye una historia que no quiere acabar con la muerte. Al ser la obra de Unamuno autobiográfica, se muestra que el ser

\footnotetext{
51 Ricoeur, P. (1967). Filosofía de la voluntad. Paris: Montaigne: 407.

52 Fornari, A. (2008). «Venir al mundo-de-la-vida. Ontología del nacimiento y ampliación de la razón». Tópicos. N. 16.

53 Ricoeur, P. (1988). Lo voluntario y lo involuntario. II. Poder, necesidad y consentimiento. Buenos Aires: Docencia.

54 Romano, C. (2008). Lo posible y el acontecimiento. Santiago: Ediciones Universidad Alberto Hurtado.

55 De Unamuno. Del sentimiento trágico de la vida.
} 
humano desde que nace está escribiendo su historia, establece un sentido del vivir como compresión de cada etapa vivida, de ahí que el hijo llorará al padre y luego el padre llore al hijo. Son etapas innegables de la vida que se constituyen en fundamento de la existencia ante todo frente al hecho de morir, como lo presenta el mismo Unamuno a continuación:

La estatua perpetúa a un hombre o su figura en un momento y en una postura dada: o adolescente, o adulto, o viejo, o decrépito; sentado o de pie; en actitud de callar o de hablar, de dolor o de alegría, etc. Y yo, si hubiera de perpetuarse mi figura, preferiría fuese, a ser posible, en un cinematógrafo que abarcará mi vida toda. ${ }^{56}$

Innegable es entonces el reconocimiento asistemático que hace Unamuno de la vida, aunque reconoce que el proceso de vivir siempre estará en busca de la totalidad del hombre, pero el vivir y constituye un constante crecimiento, de ahí que sobre todo en sus Recuerdos de mi niñez y mocedades y en su Diario intimo, seguirá un recuerdo cronológico pero desordenado de las etapas de la vida para comprenderse a sí mismo y así comprender al ser humano que en constante crecimiento debe preguntarse por el hecho que tiene que morir. Aunque su estilo no se presente como un cronograma de hechos, simplemente presentará lo que siente como niño, adolescente, joven, adulto y anciano.

La aproximación autobiográfica de Unamuno no dejará de lado ningún tema de su vida para comprenderse a sí mismo, desde su orfandad, la Guerra Civil, la influencia de lo femenino en su vida, la abuela, el sentimiento patriótico, de la educación en Madrid, Concepción Lizárraga, la muerte de Raimundo, el nacimiento de los hijos, el rectorado en Salamanca, el destierro, las pugnas políticas, el entierro de su esposa, la muerte de los otros ${ }^{57}{ }^{58}$. Serán intimidades que aparecen tal cual aparecen la vida, circunscribiéndose al hecho de tener que morir como cuestión vital.

La construcción del hombre de carne y hueso es un camino que se dirige a la plenitud del ser humano donde nadie puede llegar sin haber caminado, sin haber cumplido el proceso: "Y no sirve decir que acabaría por hacerse ave; si es que no había en ello un proceso de continuidad ${ }^{59}$. La continuidad será el paso de la construcción de la plenitud de lo humano, pero esta continuidad como todo el hombre de carne y hueso no será estática, sino que caminará siempre en el movimiento, el cambio que se da cada vez que pasamos de una etapa a otra; en otras palabras, cuando crecemos:

$\mathrm{Ni}$ a un hombre, ni a un pueblo — que es, en cierto sentido, un hombre también- se le puede exigir un cambio que rompa la unidad y la continuidad

56 De Unamuno, M. (2009). Sobre la concecuencia, la sinceridad. Salamanca: Fundación José Antonio de Castro, 946.

57 De Unamuno, M. (2009). Recuerdo de mi niñez y mocedades. Salamanca: Fundación Antonio de Castro.

58 De Unamuno. Diario Íntimo.

59 De Unamuno. Del sentimiento trágico de la vida, 282. 
de su persona. Se le puede cambiar mucho, hasta por completo casi; pero dentro de continuidad ${ }^{60}$.

La plenitud de la vida humana será en todo sentido el camino por este destino vital hacia la plenitud, pero también hacia la muerte, de ahí que Unamuno, comprenderá que la totalidad y la continuidad es constante cambio hacia la totalidad del ser. El problema ontológico de ser en la totalidad no será estaticidad sino más bien un camino que se completa en la vida como tal donde la lucha, la contradicción, el duelo y la agonía fundamentan el movimiento vital.

Claramente se puede visualizar que ontológicamente Unamuno recurre al principio de unidad y continuidad en el proceso de construcción de ser humano, verá que a pesar de mantener la unidad en lo que es, caminará siempre a la construcción en la continuidad:

Lo que determina a un hombre, lo que le hace un hombre, uno y no otro, el que es y no el que no es, es un principio de unidad y un principio de continuidad. Un principio de unidad primero, en el espacio, merced al cuerpo, y luego en la acción y en el propósito. ${ }^{61}$

La continuidad se constituye en principio de acción donde el ser no es acabado, sino que más bien se presenta como una construcción constante donde el hombre no nace completamente constituido, sino que siempre estará en acción constante por hacerse, por constituirse en una plenitud y es aquí que no quiere morir pues como plenitud se niega a desaparecer, se niega a morir.

Ésta se constituirá en el tiempo como fundamento del crecimiento humano, donde pasado, presente y futuro son momentos de la historicidad del ser humano que no quiere morir. No existirá en Unamuno una prevalencia o fascinación por un tiempo como tal sino por el hecho de que todos son parte de esa continuidad, de ahí que el pasado en el nacimiento me cuestionó por no ser antes de nacer, el presente me acongoja cuando pienso que en un futuro se que moriré: «Llevamos dentro enterrados los que fuimos, nuestros yos de antaño, y ¿qué cadena hay entre ellos? La de la continuidad, se dice. Cada uno de nosotros es una generación. ¡Y sólo en esta cadena vivimos, oh, dulce pasado! ${ }^{62}$. El problema será el tiempo del futuro en el que sabemos que nuestra vida va a terminar, es decir, que ontológicamente dejaremos de ser. Por lo que siempre presentará el futuro como aquello que, aunque no tengamos conciencia nos encaminamos hacia ello, pero siempre como interrogante pues no habrá conciencia, entonces quedará siempre la pregunta vital: «¿No hay acaso un sentido oscuro de perpetuidad hacia el pasado, de preexistencia, junto al sentido de perpetuidad hacia el futuro, de per-existencia o sobre-

\footnotetext{
60 Ibid.

61 Ibid.

62 De Unamuno, M. (2009). Sensaciones de Bilbao. Salamanca: Fundación Jose Antonio de Castro, 998.
} 
existencia?» ${ }^{63}$. De ahí que en él queda claro el punto de partida: nacimiento. El punto de llegada: muerte. Y el proceso: la vida del hombre: «Y el nacer es mi suceso cardinal en el pasado, como el morir será mi suceso cardinal en el futuro» ${ }^{64}$. Entre puntos cardinales se moverá la continuidad del ser que no querrá morir.

\subsubsection{Los otros como alternativa: la memoria, la obra de arte y la reproducción}

Es fundamental comprender que la vida es una lucha por no morir y mantener la pervivencia, de ahí que Unamuno buscará también la pervivencia en los «otros». C. Martínez explica que Unamuno se preocupará «del otro. Y es que, de origen, la razón es literalmente instrumental; una herramienta para la preservación de la existencia ${ }^{65}$. Revisaremos las alternativas que se actualizan en los otros para encontrar la pervivencia.

Unamuno en su búsqueda de inmortalidad retoma también el sentido de pervivencia en la memoria de las futuras generaciones, como lo hacían los guerreros griegos buscando gloria para ser recordados, después de la muerte, por las glorias que han plasmado en las generaciones venideras, comprendiendo que esto se constituye en un fundamento de la inmortalidad del hombre griego, de ahí que busca mantenerse en la memoria por medio de los monumentos, poemas y cantos como lo presenta Homero en sus cantos épicos: La Ilíada y la Odisea. Donde para los guerreros el peor castigo es caer en el olvido en la memoria de las generaciones venideras, de ahí que la batalla del guerrero es con el destino, donde no se quiere caer en el olvido.

Unamuno como vimos en la definición de agonía será fiel a la concepción griega. No puede vivir eternamente el ser humano, sino que hay una alternativa ésta es vivir en la memoria, como a continuación se evidencia:

Y de aquí esa tremenda lucha por singularizarse, por sobrevivir de algún modo en la memoria de los otros y los venideros, esa lucha mil veces más terrible que la lucha por la vida, y que da tono, color y carácter a esta nuestra sociedad, en que la fe medieval en el alma inmortal se desvanece. ${ }^{66}$

Aunque se desvanezca el hombre no quedará más que la búsqueda de permanecer en la memoria de la futura sociedad, pero siempre el hombre, aunque no comprenda racionalmente su deseo de inmortalidad, buscará la fama de una manera indirecta para constituirse desde la fe, una fama que le constituya como en un ser que hizo algo que lo ponga por sobre los demás para poder ser recordado, hacer algo excepcional que le de fama: «peleamos con los muertos, que son los que nos hacen sombra a los vivos. Sentimos celos de

63 De Unamuno, M. (2009). Continuación. Salamanca: Fundación José Antonio de Castro, 611.

64 De Unamuno. Recuerdo de mi niñez, 397.

65 Martinez, C. (2004). «Finitud y muerte como motor de vida en Miguel de Unamuno». Avatares, Num. 23, 55-64.

66 De Unamuno. Del sentimiento trágico de la vida, 317. 
los genios que fueron, y cuyos nombres, como hitos de la historia, salvan las edades ${ }^{67}$.

Realmente se constituye en una cruel competencia por el innato deseo de inmortalidad del ser humano. De hecho Unamuno afirmará tajantemente que sí es posible hacerlo desde esta pervivencia en la memoria de los «otros» y presentará hechos clásicos desde Caín y Abel para darnos una mirada de la historia de la literatura y la filosofía, para que el artista se constituya en una perpetuación ante el terror ante la nada y desaparecer, entonces no nos queda más que salvar nuestra memoria, hasta que dure el linaje humano, pues en este sentido, la pervivencia es la de todos los seres humanos en la historia ${ }^{68}$.

Unamuno tomará en cuenta todas las alternativas ante el problema de la inmortalidad y de hecho como se explicó anteriormente, se fijará en esta vanidad del hombre por dejar fama, de imponerse y dejar en la memoria el nombre para el futuro. De hecho, todos pueden hacer esto para inmortalizarse entrando en una competición en la que encarnizadamente unos con otros lucharán para realizar excepcionalidades con el fin de perpetuarse, pero no hay alternativa, ya que se constituye en un fundamento del orgullo y vanidad del ser humano. Aunque no esté tan abierto a esta posibilidad Unamuno revela en su obra un deseo por seguir este camino ${ }^{69}$. Es importante comprender que Unamuno siempre barajará en su obra esta posibilidad y no sólo porque es una alternativa fehaciente de pervivencia sino también por la desesperación que le lleva a justificar tal deseo; muchas veces sin encontrar otra salida.

Unamuno indaga también la posibilidad de encontrar la pervivencia en la obra de arte, es decir, que el hombre viva en su obra que no sucumbe al tiempo y se constituye en expresión de inmortalidad. «El autor se perpetúe en los personajes y en la obra, y que éstos adquieran vida propia e independiente ${ }^{70}$. El autor jugará con esta alternativa en su obra, buscará siempre entrar en cada uno de los lectores que se presentan ante su obra: "soy yo quien en ti vibro», decía en un poema, buscando siempre apoderarse del lector para en cierto modo pervivir en él. Una constante actualización del yo en el «otro» que lee la obra unamuniana. Es por eso que la literatura de este autor no será una narración del hecho que entretiene, sino que es una historia que interpela al lector y que busca interrogar lo más humano del lector en donde cada lector, cada individuo, cada ser humano que recoge la obra es novelista de su vida ${ }^{71}$,

\section{Ibid.}

68 Ibid.

69 JuAN-NAVARro, S. (1998). «La reflexión sobre la inmortalidad en la obra de Unamuno: Filosofía de la existencia, epistemología y pensamiento religioso" Cuadernos de ALDEEU. Volumen XVI. N. 1 y 2. https://www.academia.edu/176650/La_reflexi\%C3\%B3n_sobre_la_ inmortalidad_en_la_obra_de_Unamuno_Filosof\%C3\%ADa_de_la_existencia_epistemolog\% C3\%ADa_y_pensamiento_religioso

70 JuAN-NAVARRO. «La reflexión sobre la inmortalidad», 238.

71 Savignano, A. (2010). "Filosofía y religión en Unamuno: el nadismo», Cuadernos de la Catedra Miguel de Unamuno, N. 48 (1). http://revistas.usal.es/index.php/0210-749X/article/ view/8451, Universidad Pontificia de Salamanca. 
de su propia vida, ahí el fundamento de la nivola, donde cada personaje se hace expresión de vida misma. Pero el punto de partida será siempre el entrar en el mundo interno del otro. Entonces nos encontramos con la alternativa de pervivir en el que toma entre sus manos la obra, el autor se presenta en cada uno de sus párrafos, de ahí que él mismo se dará cuenta de que «el que lee una novela puede vivirla, revivirla y quien dice una novela dice una historia, y el que lee un poema, una criatura-poema es criatura y poesía creación puede recrearlo. Entre ellos el autor mismo» ${ }^{72}$.

Pero el problema de la inmortalidad se extiende a todas las manifestaciones del arte como posibilidades para encontrar la pervivencia donde cada una de las producciones del autor se convierten en continuidad de la vida, "quiere, cuando menos, dejar una sombra de su espíritu, algo que le sobreviva ${ }^{73}$. Pues, aunque no esté en la memoria de los otros perennemente, cuando la obra de arte se presente ante el espectador, ahí revivirá el autor, vivirá para siempre en una actualización del presente constante en el espectador, de ahí que Unamuno presentará el nacimiento del arte como fundamento del hambre de inmortalidad:

¿De dónde ha nacido el arte? De la sed de inmortalidad. De ella han salido las pirámides y la esfinge que a su pie duerme. Dicen que ha salido del juego ¡El juego! El juego es un esfuerzo por salirse de la lógica, porque la lógica lleva a la muerte. Me llaman materialista. Sí, materialista, porque quiero una inmortalidad material, de bulto, de sustancia... Vivir yo, yo, yo, yo. ${ }^{74}$

La lógica y el estudio estético racional de la obra como tal queda de lado ante el deseo de pervivencia del autor de la misma, como un hambre de inmortalidad común en todos los seres humanos: «Y esta creación o recreación no es sólo de la obra de arte, sino de nosotros mismos, por cuanto enriquece nuestro espíritu con preciosidades tan por encima de toda ponderación ${ }^{75}$. Valga recalcar el enaltecimiento que Unamuno hace al arte como una manera preciosa de demostrar este deseo de inmortalidad.

Pero a pesar de revisar y tentar esta alternativa como pervivencia Miguel de Unamuno verá que este camino de cierto modo despersonaliza y aleja de aquel llamado a mantenerme inmortal desde la conciencia. Entenderá que pocas son las salidas ante tal deseo; pocas veces se encuentra alternativa para satisfacer este hambre de inmortalidad, llegando incluso a presentarlo de la siguiente manera: El deseo más ardiente de sus condenados es el de que se les recuerde aquí, en la tierra, y se hable de ellos, y es esto lo que más ilumina las tinieblas del infierno ${ }^{76}$. Refiriéndose a los condenados que aparecen en el

72 Junan-Navarro, M. (1999). Como se hace una novela. Salamanca: Fundación José Antonio de Castro, 549.

73 De Unamuno. Del sentimiento trágico de la vida, 316.

74 De Unamuno, M. (1934), Amor y Pedagogía. Madrid: Espasa-Calpe, 546.

75 De Azaola, J. M. (2002), «Acercamiento al ideario estético de Miguel de Unamuno», Cuadernos de la Catedra Miguel de Unamuno, N. 37: 33. http://revistas.usal.es/index.php/0210749X/article/view/1486. Universidad Pontifica de Salamanca.

76 De Unamuno. Del sentimiento trágico de la vida, 316. 
tradicional cuadro del infierno que se presenta en las iglesias católicas, todo eso es aceptable antes que perderse en la muerte. Interrogantes quedarán en torno al pensamiento unamuniano, aunque las posibilidades sean tomadas en cuenta a lo largo de la vida, el punto de partida es el hambre de inmortalidad como lucha por no morir. Donde lector y autor se perpetúan ya sea en la obra o en el autor respectivamente ${ }^{77}$.

Entre las otras alternativas que Miguel de Unamuno explora para encontrar la pervivencia, mira a los hijos como continuación de la existencia, las futuras generaciones se presentan como una extensión de nuestra vida. En su obra verá siempre la importancia de la paternidad como una vocación que permita criar seres humanos integrales, de ahí que el nacimiento y la reproducción humana encontrarán fundamento en los hijos como camino para la perpetuación, como se lee a continuación:

¡Sacrifícate por tus hijos! Y te sacrificarás por ellos, porque son tuyos, parte prolongación de ti, y ellos a su vez se sacrificarán por los suyos, y estos por los de ellos, y así irá, sin término, un sacrificio estéril del que nadie se aprovecha. ${ }^{78}$

No es una concepción egoísta que busca criar un hijo para hacerlo una continuidad del padre, sino que busca generar una conciencia de una paternidad real que permita comprender que los hijos serán parte de nosotros que quedan en la vida y al quedarse deben vivir bien como mi «yo» quisiera vivir. La realización de cada una de las generaciones garantiza el crecimiento del otro con la parte que el padre le dio.

Unamuno explora esta alternativa desde su existencia, como siempre desde el hombre de carne y hueso en su cotidianidad. Así, se presentará como un padre amante, lo cual se evidencia en la siguiente escena: «Unamuno invitaba a sus hijos a jugar delante de su hermano Raimundo para distraerle. Menéndez Pidal y Pérez de Ayala han recordado cómo Don Miguel se entendía magníficamente con los niños $»^{79}$. Así también cuando muere Raimundo una parte de Don Miguel morirá, como si perdiese algo muy importante en su ser, pues se constituye en la muerte de Raimundo una posibilidad de pervivencia.

En este sentido Unamuno es muy realista al comprender que la vida necesariamente requiere perpetuidad y reactualización en la prole buscando siempre generar una continuidad de la existencia, es decir, los hijos al vivir en ellos, vive una parte de mi ${ }^{80}$, ya sea el apellido, la memoria, los rasgos físicos, psicológicos o demás características, que permitirán que los hijos se constituyan en una continuidad del padre o la madre. No es una continuidad

\footnotetext{
77 JUAN-NAVARRo. «La reflexión sobre la inmortalidad».

78 De Unamuno. Del sentimiento trágico de la vida. 311.

79 Navarro, C. (2015). "Las edades del hombre, el escritor: Miguel de Unamuno». Norte de salud mental. Vol. XIII, $n^{\circ}$ 51. 90.

80 Mezouita, P. (2007). «El principio de continuidad historica en Unamuno». Cuadernos de la Cátedra Miguel de Unamuno, 45, I-2007, pp. 53-87.
} 
ingenua, sino que parte de mi ser se entrega a la inmortalidad, aunque no sea mi todo; será una parte de mí. De ahí la preocupación por las generaciones pues el abuelo, el padre, los hijos, nietos se constituyen en una historia de vida que lucha por no desaparecer en la historia y se actualiza en el hombre cada una de las generaciones. «Todo muda y sólo la mudanza permanece. Todo pasa y todo vuelve. Los hijos reproducen la historia: ellos recuperan lo que los padres no volverán a ser ${ }^{81}$. Los hijos al constituirse en continuidad de los padres, son una vaga esperanza de perpetuarse en la vida, serán los guardadores del nombre de sus padres y vengadores de su honra ${ }^{82}$. Entonces en este punto se conjugan la paternidad, el nombre, la memoria y la honra. Fundamentos de las alternativas de pervivencia que Miguel de Unamuno explorará siempre. La paternidad y los hijos son en sí un fundamento de la pervivencia para comprender que todos los seres humanos se preocupan por la inmortalidad del alma.

Aunque en el pensamiento unamuniano, se tome en cuenta la importancia de la paternidad y la continuidad en los hijos, no constituyen un fundamento de la inmortalidad del ser humano, porque cuando el ser humano quiere vivir, Unamuno piensa en el hombre concreto de carne y hueso que tiene conciencia de su realidad, por lo que no se consolará con la idea de la continuidad en los hijos; se acercará a la idea, pero es insostenible esta opción: «Ni el sobrevivir en la fama o en los hijos, les parecía compensación suficiente a los sufrimientos del esfuerzo ${ }^{83}$. Un esfuerzo por pervivir con la conciencia actual, vivir en la propia historia es la agonía de Unamuno pues no encontrará alternativa ni en los hijos.

Entonces regresamos al interés primario del bilbaíno, el hambre de inmortalidad, incluso en el acto de engendrar a otro ser, que se constituye en un acto de vida pura. El comprende e identifica este acto con el hecho de tener que morir, el nacimiento del otro engendrado se constituye en garantía de pervivencia del engendrador, del hombre de carne y hueso que además de las funciones vitales que el autor enumera, también ama y se reproduce para eternizarse en los hijos.

En Miguel de Unamuno, no existe una conceptualización del hecho de morir sino más bien buscará desde la vida comprender el sentido de la muerte como algo muy real en aquel hombre de carne y hueso que él profesó. Siempre estará explicándose de una manera muy corpórea el problema de la muerte dejando de lado cuestiones abstractas o fideistas de la muerte, pues el hecho que le preocupaba era el de la muerte individual del hombre ${ }^{84}$.

La realidad está ahí, pero a pesar de la dicotomía agónica simplemente no se resignará nunca a perder la vida. Dando paso a un hecho más fuerte en el

81 Baliñas, C. (1998). «Vivencia reflexiva del tiempo: Unamuno, Azorín, Valle - Inclán». Anuario Filosófico N. 31: 217. http:// search.proquest.com/openview/17b1b4545ecbee5e4cb3 b82d52e $5 \mathrm{da} 25 / 1$ ?pq-origsite $=$ gscholar\&cbl $=1818226$.

82 De Unamuno, M. (2009). En torno al castisismo. Salamanca: Fundación Antonio de Castro.

83 Baliñas. «Vivencia reflexiva del tiempo», ed. cit. 231.

84 Villar EzcurRa. «Muerte y pervivencia en Unamuno», ed. cit. 242. 
pensador en el cual la lucha alcanza su máxima expresión, sobre todo por la rebelde y belicosa manera de enfrentarse a la idea de morir, donde surge de una manera muy aguerrida el «no quiero», simplemente presentará como un «no me da la gana de morirme», aunque la razón sea consciente de que el «yo» morirá, luchando por recordarle al hombre que va a morir, de ahí que:

En una palabra, que, con razón, sin razón o contra ella, no me da la gana de morirme. Y cuando al fin me muera, si es del todo, no me habré muerto yo, esto es, no me habré dejado morir, sino que me habrá matado el destino humano. Como no llegue a perder la cabeza, o mejor aún que la cabeza, el corazón, yo no dimito de la vida; se me destituirá de ella.$^{85}$

No encaja en una definición de muerte, pues al definirla simplemente estaría cayendo en la trampa de la que él mismo huye, el racionalizarla. Pues cuando racionalice el hecho de morir lo definirá convirtiéndola en una idea abstracta lejos de la vida del hombre de carne y hueso, pues dará muchas pruebas Unamuno de que las ideas o la razón se constituyen en fundamento de muerte, la inmortalidad no puede ser comprendida desde la razón sino desde el ser humano total, "el pensamiento unamuniano una reflexión sistemática y racional del problema de la inmortalidad. ¡Jamás! Esto sería traicionar su mismo estilo el cual, de raíz, desconfía de la razón, dada su incapacidad de penetrar en el misterio de la vida $»^{86}$.

El grito unamuniano no va encaminado a comprender la muerte como un hecho inherente a la vida, sino que es una gritería feroz en torno a no querer morir, no es el hombre que comprende, sino el hombre que sufre al tener que morir, grita por no hacerlo pues eso sería una resignación conceptual cuando en Unamuno es una rebeldía vital del hombre que anhela perpetuarse en la máxima expresión de la vida, la inmortalidad.

En su obra se encontrará una constante agonía, en el sentido que es una lucha por sobrevivir, por pervivir donde él mismo, que presentará que la vida es una lucha contra sí misma, contra el hecho de saber que vamos a morir y no queda otra salida, la agonía y lucha constante ${ }^{87}$. Entonces tenemos un punto de partida: el saber que vamos a morir, el hombre unamuniano tiene la certeza que morirá, desde aquí se proyectará a luchar en la vida con plenitud, ésta que aguerridamente se enfrentará ante esta idea, «afirmar que la guerra es la muerte puede significar que la lucha interior nos mata, haciéndonos agonizar» ${ }^{88}$.

85 De Unamuno. Del sentimiento trágico de la vida, 379.

86 Posada, E. (2009). La fe de Don Miguel de Unamuno en su obra San Manuel Bueno, martir. Tesis de Maestria, Pontificia Universidad Santo Tomas de Aquino, 25

87 De Unamuno. Agonía del Cristianismo, 247-250.

88 Orringer, N. (2009). "Pascal, portavoz de Unamuno y clave de la Agonía del Cristianismo» Cuadernos de la Catedra Miguel de Unamuno, 42 (2): 66. http://revistas.usal.es/ index.php/0210-749X/article/view/1525. Universidad Pontificia de Salamanca. 


\section{BiBLIOGRAFÍA}

AgüEro, E. (1968). El pensamiento filosófico y religioso de Unamuno. New York: American Press Publications.

BaLiñas, C. (1998). «Vivencia reflexiva del tiempo: Unamuno, Azorín, Valle - Inclán». Anuario Filosófico N. 31: 217. search.proquest.com/openview/17b1b4545ecbee5e4cb $3 \mathrm{~b} 82 \mathrm{~d} 52 \mathrm{e} 5 \mathrm{da} 25 / 1$ ?pq-origsite $=$ gscholar\&cbl $=1818226$.

Blanco Ilari, J. (2011). Lo agonal y lo ireneico en la filosofía. Tábano, 7: 66 http:// bibliotecadigital.uca.edu.ar/repositorio/revistas/agonal-ireneico-filosofia-ilari.pdf, Universidad Católica de Argentina.

Camino, A. (2013). «Los orígenes de la ontología de Unamuno» Scientia Helmantica. Revista Internacional de Filosofía, N. 2: 104, http://revistascientiahelmantica.usal. es/docs/Vol.02/06.Camino_Aparicio.Origenes_de_la_ontologia_de_Unamuno.pdf. Universidad Pontificia de Salamanca.

Cerezo Galán, P. (1996). Las Mascaras de lo Trágico. Madrid: Trotta.

De Azaola, J. M. (2002). "Acercamiento al ideario estético de Miguel de Unamuno», Cuadernos de la Catedra Miguel de Unamuno, N. 37: 33. http://revistas.usal.es/index. php/0210-749X/article/view/1486. Universidad Pontifica de Salamanca.

De Unamuno Perez, M. de C. (1999). «Unamuno lector de Balzac: La sed de eternidad». Cuadernos de la Catedra Miguel de Unamuno, vol 33(0). (1998). http://revistas.usal. es/index.php/0210-749X/article/view/1697. Universidad Pontificia de Salamanca. De Unamuno, Miguel. Como se hace una novela. Salamanca: Fundación José Antonio de Castro.

De Unamuno, M. (1999). Cancionero. Salamanca: Fundación José Antonio de Castro.

De Unamuno, M. (1999). Como se hace una novela. Salamanca: Fundación José Antonio de Castro.

De Unamuno, M. (2009). Diario Íntimo. Salamanca: Fundación José Antonio de Castro.

De Unamuno, M. (2009). Agonía del Cristianismo. Salamanca: Salamanca.

De Unamuno, M. (1934). Amor y Pedagogía. Madrid: Espasa-Calpe.

De Unamuno, M. (2009). Continuación. Salamanca: Fundación José Antonio de Castro.

De Unamuno, M. (2009). Del sentimiento trágico de la vida. Salamanca: Fundación Antonio de Castro.

De Unamuno, M. (2009). En torno al castisismo. Salamanca: Fundación Antonio de Castro.

De Unamuno, M. (2009). Madrid. Salamanca: Fundación José Antonio de Castro.

De Unamuno, M. (2009). Sensaciones de Bilbao. Salamanca: Fundación Jose Antonio de Castro.

De Unamuno, M. (2009). Sobre la concecuencia, la sinceridad. Salamanca: Fundación José Antonio de Castro.

De Unamuno, M. (2009). Recuerdo de mi niñez y mocedades. Salamanca: Fundación Antonio de Castro.

Diez Fisher, F. (2012). «La filosofía y los nacidos. ¿Porqué olvidaron los filósofos el nacimiento?» Franciscanum. Vol. N. 157 (2012).

Fornari, A. (2008). «Venir al mundo-de-la-vida. Ontología del nacimiento y ampliación de la razón». Tópicos. N. 16.

GeVAert, J. (2013). El problema del hombre. Salamanca: Sígueme.

GuY, A. Historia de la Filosofía Española. Madrid: Anthropos, s.f.

JuAN-NAVARRo, S. (1998). "La reflexión sobre la inmortalidad en la obra de Unamuno: Filosofía de la existencia, epistemología y pensamiento religioso» Cuadernos de 
ALDEEU. Volumen XVI. N. 1 y 2. https://www.academia.edu/176650/La_reflexi\% C3\%B3n_sobre_la_inmortalidad_en_la_obra_de_Unamuno_Filosof\%C3\%ADa_de_ la_existencia_epistemolog\%C3\%ADa_y_pensamiento_religioso

Marías, J. (1953). El existencialismo en España. Bogota: Universidad Nacional de Colombia.

Marías, J. (1948). La Filosofía española actual. Buenos Aires: Austral.

Marías, J. (1971). Miguel de Unamuno. Madrid: Espasa-Calpe.

Martinez, C. (2004). «Finitud y muerte como motor de vida en Miguel de Unamuno». Auatares, Num. 23: 55-64.

Mezouita, P. (2007). «El principio de continuidad histórica en Miguel de Unamuno», Cuadernos de la Cátedra Miguel de Unamuno, 43, I-2007, pp. 53-87.

Navarro, C. (2015). «Las edades del hombre, el escritor: Miguel de Unamuno». Norte de salud mental. Vol. XIII, $n^{\circ} 51$.

OrRinger, N. (2009). «Pascal, portavoz de Unamuno y clave de la Agonía del Cristianismo» Cuadernos de la Catedra Miguel de Unamuno, 42 (2): 66, http://revistas.usal.es/index. php/0210-749X/article/view/1525. Universidad Pontificia de Salamanca.

Pabon, J. (1967). Diccionario Manual Griego. Madrid: Vox.

Pascual Mezouita, E. (2007). El principio de continuidad historica en Unamuno, Cuadernos de la Catedra Miguel de Unamuno, vol 43: 68. http://revistas.usal.es/index. php/0210-749X/article/view/1561: Universidad Pontificia de Salamanca.

Posada, E. (2009). La fe de Don Miguel de Unamuno en su obra San Manuel Bueno, martir. Tesis de Maestria, Pontificia Universidad Santo Tomas de Aquino.

Reale G. and Antiseri D. (1988). Historia del Pensamiento Filosófico y Cientifico: Desde el Romanticismo hasta hoy. Barcelona: Herder.

Ricoeur, P. (1967). Filosofía de la voluntad. Paris: Montaigne.

Ricoeur, P. (1988). Lo voluntario y lo involuntario. II. Poder, necesidad y consentimiento. Buenos Aires: Docencia.

Rocci (1944). Vocabolario. Greco-Italiano. Genova: Societá Anima Dante Alighieri.

Romano, C. (2008). Lo posible y el acontecimiento. Santigo: Ediciones Universidad Alberto Hurtado.

SANMARTín, R. (2016). «El lenguaje incorporado desde y para la cognición incorporada». Sophia: Colección de filosofía de la educación. 21-64. DOI: 10.17163/soph.n20.2016.01.

SAvignano, A. (2010). "Filosofía y religión en Unamuno: el nadismo», Cuadernos de la Catedra Miguel de Unamuno, N. 48 (1), http://revistas.usal.es/index.php/0210-749X/ article/view/8451, Universidad Pontificia de Salamanca.

Sinoza, B. (1980). Ética. Demostrada según el orden geométrico. Madrid: Orbis.

VIllar Ezcurra, A. (2007). "Muerte y pervivencia en Unamuno», Contrastes: Revista Internacional de Filosofia, $\mathrm{N}^{\circ} 12$.

Villar Ezcurra, A. (2014). «El orden del amor en Miguel de Unamuno». Dialegesthai. Revista telematica di filosofia [in linea], anno 16. 14 de 04 de 2016. <http:// mondodomani.org/dialegesthai/>, [**41 B], ISSN.

Universidad Politécnica Salesiana - Ecuador

fviteri@ups.edu.ec

Universidad Pontificia Bolivariana - Colombia edward.posada@upb.edu.co

[Artículo aprobado para publicar en diciembre de 2016]
Frank Bolívar Viteri Bazante

Edward Andrés Posada Gómeze 